\title{
PEDAGOGIA E FACULDADES DE EDUCAÇÃO: VICISSITUDES E POSSIBILIDADES DA FORMAÇÃO PEDAGÓGICA E DOCENTE NAS IFES
}

\author{
Márcia Angela da S. Aguiar \\ Márcia Maria de Oliveira Melo*
}

\begin{abstract}
RESUMO: $\mathrm{O}$ artigo discute a centralidade da pedagogia na formulação e implementação de uma política de formação dos profissionais da educação que seja expressão do projeto político-pedagógico mais amplo da instituição universitária. Problematiza a materialização dessa política nas Instituiçôes Federais de Ensino Superior (IFES), considerando o contexto sócio-político e educacional, a pedagogia universitária e a indissociabilidade entre ensino-pesquisaextensão, compre-endida pela transversalidade do pedagógico e da inter-transdisciplinaridade possível entre as áreas de conhecimento no âmbito universitário. Reflete sobre a necessidade de materializar essa política, tendo como horizonte os princípios da gestão democrática, do trabalho coletivo, da avaliação contínua e da docência.
\end{abstract}

Palavras-chave: Pedagogia. Faculdades/centros de educação. Política de formação dos profissionais da educação. Projeto político-pedagógico. Gestão educacional e de ensino.

\section{Pedagogy and education COlleges: Vicissitudes AND POSSIBILITIES OF PEDAGOGICAL AND TEACHER TRAINING AT THE IFES}

ABSTRACT: This paper discusses the centrality of Pedagogy in the formulation and implementation of policies to train education professionals that express a wider political-pedagogical project of the university institution. It explores the sociopolitical and educational context, university pedagogy and the impossibility to separate

\footnotetext{
* Professora do Programa de Pós-Graduação em Educação do Centro de Educação da Universidade Federal de Pernambuco (UfPe). E-mail: marcia_angela@uol.com.br

** Professora do Programa de Pós-Graduação em Educação do Centro de Educação da UfPE. E-mail: melomarcia@hotmail.com
} 
Pedagogia e faculdades de educação: vicissitudes e possibilidades...

teaching-research-extension entailed by the transversality of both pedagogy and the possible inter-transdisciplinarity between knowledge areas in universities to question the actualization of such policies in the Instituiçôes Federais de Ensino Superior (IFES - Federal Institutions of Higher Education). It reflects about the needs to realize this policy with the democratic management, group work, continuous assessment and teaching principles as a horizon.

Key words: Pedagogy. Colleges/educational centers. Policies to train education professionals. Political-pedagogical project. Educational and teaching management.

\section{Introdução}

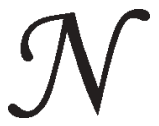

esse estudo, parte-se do pressuposto de que as faculdades/centros/ departamentos de educação, de universidades públicas no Brasil, tendem a ocupar uma posição central no contexto de criação de

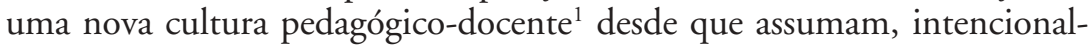
mente, nos planos teórico e organizacional, políticas de formação dos profissionais da educação - quer sejam de futuros profissionais (pedagogos professores e professoras da educação básica), quer sejam de docentes universitários -, ancoradas numa base comum de cunho eminentemente pedagógico. Assume-se que tal posicionamento constitui a expressão visível da construção conjunta de um projeto político institucional e acadêmicopedagógico (universidade/centro de educação) pautado por uma concepção sócio-histórica de educação, ${ }^{2}$ que se traduz em uma diretriz políticopedagógica que permeia as práticas institucionais, na perspectiva da cidadania e emancipação humana de todo e qualquer profissional da educação. Concepção essa que se expressou no debate acadêmico-político, a partir, sobretudo, da década de 1980, e influenciou as reformas que se processaram nos centros de formação das universidades públicas.

Entende-se que essa base comum ${ }^{3}$ porta a intenção de manifestarse em todos os processos e práticas formativas no interior da universidade e de se materializar, de forma mais concreta, nos currículos dos cursos de pedagogia e das licenciaturas. Neste caso, contribui para o desenvolvimento dos profissionais da educação e da sua profissionalidade ${ }^{4}$ e profissionalização, ${ }^{5}$ com vistas à construção de saberes necessários à sua profissão e ao processo de desenvolvimento de sua (relativa) autonomia.

$\mathrm{Na}$ perspectiva sócio-histórica da educação, a construção desses saberes se efetiva no contexto da indissociabilidade entre ensino, pesquisa 
e extensão e da sedimentação/dinamização da cultura (Weber, 2000), bem como na recontextualização dos discursos especializados em discursos pedagógicos, conforme Bernstein (1996). Isto significa favorecer a articulação entre os saberes curriculares, especializados, pedagógico-profissionais, institucionais, sociais, culturais (Nóvoa, 1995a; Tardif, 2002; Pimenta, 1999; Melo, 2000; Lüdke \& Boing, 2004), como relações de poder (Bernstein, 1995), ao longo da formação. Tal perspectiva implica considerar a complexidade das relaçóes de poder que se estabelecem nos diversos campos científicos (Bourdieu, 1994) e entre os loci de formação no interior da universidade.

Nesse sentido, atente-se para a questão de que a política de formação dos profissionais da educação, a ser materializada nessas instâncias, envolve o curso de Pedagogia em interface com as licenciaturas diversas, a pós-graduação em Educação e, em algumas instituições de ensino superior, o Colégio de Aplicação (que oferece educação básica), como também requer a efetivação de um projeto político-pedagógico mais amplo, que se estende no interior da universidade, como instância educativa, numa articulação orgânica com os sistemas de ensino e as diversas práticas sócio-educativas. Este projeto, como um norte sempre revisitado, ancora-se: nas finalidades educativas; na perspectiva interdisciplinar e na flexibilização dos currículos, práticas e espaços; na efetivação de uma avaliação permanente das práticas pedagógicas-educativas; na gestão democrática e no trabalho coletivo (Zabala, 1998; Santomé, 1998; Sacristan, 1997; Freitas, 1999; Aguiar, 2002a). Tem raízes também na valorização e fortalecimento da especificidade teórico-prática do conhecimento pedagógico e de sua extensão nas diversas práticas institucionais e docentes da universidade; na formação pedagógica inicial e contínua articuladas, de modo a envolver também a docência universitária. E, por fim, ancorase no movimento de resistência a qualquer política de desvalorização da universidade pública e do magistério, pelo prisma material e simbólico (ANFOPE, 1992).

Diante disso, este artigo discute o papel dos centros de educação, suas dificuldades e possibilidades de proceder reformulaçóes na estrutura pedagógico-organizacional, considerando a complexidade do paradigma da pedagogia, para responder às exigências legais, ao debate crítico nacional contemporâneo e à diversidade das demandas educacionais e sociais. Assim, num primeiro momento, analisa o papel desses centros na universidade pública, no tocante à política de formação dos profissionais 
Pedagogia e faculdades de educação: vicissitudes e possibilidades...

da educação, levando em conta, além das questóes já enfocadas, a necessidade de atender expectativas e demandas dos sistemas de ensino mediante a oferta de formação inicial/continuada.

Discute, ainda, as possibilidades de fortalecimento da unidade do pedagógico, no interior dessas instâncias, em meio às multideterminaçôes e multireferencialidades de princípios, valores, normas, conhecimentos, como um discurso pedagógico complexo que recontextualiza conhecimentos especializados em conhecimentos pedagógicos (Bernstein, op. cit.), que favorece a construção de identidades individuais e coletivas, que produz e veicula culturas e que orienta a implementação da gestão humanizada das diversas práticas institucionais (Melo, 2002).

O texto analisa, entre as dificuldades mais amplas da materialização dessa pedagogia, aspectos da cultura institucional e docente que porta, ainda, a lógica da fragmentação, da disciplinaridade e do individualismo que permeia as práticas e os conhecimentos dos sujeitos no interior das instâncias educativas.

Os centros/faculdades e departamentos de educação e a política de formação dos profissionais da educação

Compreender o papel e a reestruturação dos centros, faculdades e departamentos de educação, ${ }^{6}$ no contexto das exigências das reformas educativas na contemporaneidade e do debate educacional crítico, requer pensar o projeto político-pedagógico da instituição, como espinha dorsal, sempre revisitado e re-construído, bem como as suas dificuldades e possibilidades de avanços, na perspectiva da materialização de uma formação humana e profissional integradas. Formação essa que, pelos seus princípios pedagógicos, envolve a compreensão da prática educativa como prática social, sob o prisma das múltiplas dimensōes ético-política, epistemológico-cultural, estética, profissional e humana, como também a organização do trabalho pedagógico mais amplo e docente articulados, entendidos nas suas mais diversas especificidades de área de conhecimentos e modalidades de ensino necessárias à formação do profissional da educação.

Além do que, faz-se necessário pensar uma estrutura que dê conta, de fato, da materialização dos princípios da gestão democrática (Aguiar, 2002) e do trabalho pedagógico coletivo interdisciplinar/transdiciplinar, 
que assegure a construção de práticas numa relação orgânica com os demais institutos, faculdades, departamentos da universidade (que desenvolvem também práticas formativas e de gestão) (Bicudo, 2000), e com os sistemas de ensino e também com as demais práticas sociais.

Pensar esse projeto, desse modo, é considerar concretamente aqueles loci ampliados de formação dos profissionais da educação, o seu papel, como resultado de relações articuladas dialeticamente entre as funções de ensino, pesquisa, extensão, bem como aquela que se refere à sedimentação/dinamização da cultura, onde saberes, conhecimentos, princípios, valores, competências, habilidades e práticas pedagógicas diversas se articulam e se constroem no seu interior e fora dele, como uma gramática pedagógica, cujos códigos têm uma vinculação com a estrutura de poder da sociedade e da sua cultura (Bernstein, op. cit.). Vale lembrar que, nesse processo, não obstante o peso dessas influências, há abertura para se forjar identidades individual, profissional e coletiva, numa sintonia crítica com os desafios da sociedade, sendo essas consideradas como que encarnadas nas objetividades e subjetividades das relações sociais e imbuídas ou não da intenção de contribuir para o combate aos efeitos antidemocráticos, desagregadores e anti-solidários, tão presentes no cotidiano dessas práticas.

Isso remete a refletir, ainda, sobre a historicidade das faculdades de educação que, na sua atualidade, guardam, em certa medida, a filosofia e a estrutura para as quais elas foram criadas, a partir de 1968, com a reforma universitária, numa nova organização institucional compartimentalizada em diversos departamentos, nas universidades e instituições de ensino superior, voltadas, entre outros objetivos, para atender as grandes demandas do mercado que se expandia e se tornava mais exigente em termos de formação dos recursos humanos, face ao desenvolvimento urbano-industrial e aos interesses da política e da ideologia desenvolvimentista da época (Cunha ,1983).

Se, no projeto anterior, na década de 1930, no contexto da criação de algumas universidades e faculdades de filosofia, ciências e letras (miniuniversidades), os estudos da educação estavam materializados nas secções de pedagogia e de didática voltados para a formação do professor do ensino normal e secundário e do técnico da educação; e, se esses estudos e outros, foram materializados, sob a égide da filosofia, como núcleo aglutinador, orientador das práticas acadêmicas e das diversas áreas de conhecimento, numa perspectiva interdisciplinar, humanística e de atendi- 
Pedagogia e faculdades de educação: vicissitudes e possibilidades...

mento ao princípio da pesquisa pura e desinteressada, sob a influência do modelo alemão de Humboldt (a exemplo das que foram criadas em São Paulo - USP - e no Rio de Janeiro, depois transformada na Faculdade Nacional de Filosofia), a mudança de projeto e de loci desses estudos e das práticas formativas representou a hegemonia do projeto de profissionalização/especialização, na forma como ele já vinha se esboçando com o processo de desenvolvimento econômico, industrial e urbano, a partir daquela década, e que não vislumbrava uma concepção de universidade e de educação voltada para a integralidade da formação humana e para uma prática interdisciplinar, sob o comando da filosofia.

Instaura-se, assim, um novo marco histórico e paradigmático de compreender os estudos da educação fora do contexto daquelas faculdades, junto aos diversos institutos, nas mais diversas áreas do conhecimento, numa instância agora própria, dedicada a preparar professores e pesquisadores para entender os problemas educacionais e "a prestar serviços para desenvolver projetos, aperfeiçoar e renovar os sistemas escolares e em todas as suas instâncias e níveis", como afirma Krasilchik (2000).

Nessa mudança de locus, perde-se uma oportunidade mais imediata de os cursos de formação de pedagogos e professores materializarem o princípio da interdisciplinaridade entre as áreas das ciências sociais e humanas e com as outras áreas do conhecimento. De fato, conforme Weber (2000), a convivência com professores e pesquisadores de outras especialidades e de estudantes dos diversos cursos permitiam o intercâmbio e o desenvolvimento de projetos comuns. Todavia, não obstante a perspectiva da interdisciplinaridade no interior das faculdades de filosofia, ciências e letras, permanecia a ambigüidade da estruturação do curso de pedagogia e de licenciaturas "consubstanciada na separação entre elementos do conteúdo e do método e na oferta de diplomas distintos" (Weber, op. cit., p. 128). Esta situação foi objeto de outras críticas, durante décadas (Fétizon, 1994; Brzezinski, 1996), o que se acentua, conforme Weber, a partir da publicação dos decretos n. 53/1966 e 252/1967 que “impuseram a reestruturação das universidades federais, criaram as faculdades de educação e definiram que a formação pedagógica de professores ficaria a cargo de unidade própria de ensino profissional e aplicado" (p. 128-130). Ressalte-se que essas faculdades foram criadas, de fato, a partir da Lei n. 5.540/68, no âmbito da reforma universitária.

Por outro lado, destaque-se a separação entre a formação inicial e continuada e a tímida produção do conhecimento educacional que vi- 
nha se esboçando naquele contexto, que se amplia considerando o grande investimento na pesquisa, ou seja, com a criação dos cursos de pósgraduação, a partir da década de 1970, em um novo ambiente institucional, como afirma Weber (op. cit.). Essa produção no âmbito das faculdades de educação, na visão de Weber (op. cit., p. 130), "raramente conseguiu transformar-se em suporte de atividade formadora e, menos ainda, de conformação de desenhos institucionais de formação graduada, mesmo que de caráter experimental, capazes de retificar ou trazer respostas a determinados problemas educacionais relevantes".

Os estudos de Krasilchik (op. cit.) fazem menção a esses problemas e a outras necessidades demandadas por aquelas instâncias educativas, considerando que eles

afetam suas similares no mundo inteiro e que têm merecido estudos bastante rigorosos sobre a qualidade e relevância das pesquisas, a relação com os sistemas educacionais, sobre a competência e o compromisso dos profissionais que forma e gradua, as relaçōes intra-universitárias com os institutos e faculdades que preparam seus alunos dando-lhes o chamado conteúdo, e a sua responsabilidade na formação pedagógica, relacionando teoria e prática principalmente nos estágios que são realizados nas escolas fundamentais e médias.

De fato, dentre esses desafios, uma demanda é claramente percebida como relevante: a ampliação do relacionamento da universidade com os sistemas de ensino, ${ }^{7}$ no sentido de resgatar a dívida para com a educação como direito de todos, ou seja, uma educação que considere a ampliação do acesso e a permanência com qualidade com base numa escola para todos. Marcovitch (2000), ao se debruçar sobre o papel daquelas instituiçôes de educação, afirma que elas buscam resgatar a qualidade perdida pela escola secundária na rede pública - "único meio de tornar mais democrático o acesso à universidade, também pública". Para o autor, "o esforço do corpo docente deve ser precedido por um empenho maior, em nível de governo, para que se aprimore a gestão escolar e se remunere condignamente os profissionais do magistério. Em qualquer hipótese, porém, o trabalho dos mestres é a chave da equação educacional em nosso país" (Marcovitch, op. cit., p. 7).

É bem verdade que as faculdades de educação, dentre outros espaços, são afetadas, também, pelo desprestígio da área da educação, dos saberes pedagógicos, da profissão do professor(a) e do profissional da educa- 
Pedagogia e faculdades de educação: vicissitudes e possibilidades...

ção, no interior da universidade e fora dela, não obstante serem reconhecidas, contraditoriamente, como uma área estratégica para a humanização de todas as práticas sociais e profissionais, visto serem responsáveis por dar um sentido educativo e instrucional às mesmas, conforme assinalam Bernstein (op. cit.); Tardif (1991; 2002) e Lüdke (2004).

Essa problemática encontra ainda explicação teórica em Bourdieu (1994, p. 122), quando assinala que o

campo científico, enquanto sistema de relações objetivas entre posições adquiridas (em linhas anteriores), é o lugar, o espaço de jogo de uma luta concorrencial. O que está em jogo especificamente nessa luta é o monopólio da autoridade científica definida, de maneira inseparável, como capacidade técnica e poder social; ou, se quisermos, o monopólio da competência científica, compreendida enquanto capacidade de falar e de agir legitimamente (isto é, de maneira autorizada e com autoridade), que é socialmente outorgada a um agente determinado.

Nesse sentido, a valorização ou não das práticas pedagógicas no interior da universidade, como indicam vários estudos e pesquisas $(\mathrm{Cu}-$ nha, 1998a; Fernandes, 1998) é influenciada por essas lutas concorrenciais que atingem os seus agentes sociais, de modo que, por um lado,

a posição que cada agente singular ocupa num dado momento na estrutura do campo científico é a resultante, objetivada nas instituições e incorporada nas disposiçôes, do conjunto de estratégias anteriores desses agentes e de seus concorrentes (elas próprias dependentes da estrutura do campo, pois resultam das propriedades estruturais da posição a partir da qual são engendradas). Por outro lado, as transformações da estrutura do campo são o produto de estratégias de conservação ou de subversão que têm seu princípio de orientação e eficácia nas propriedades da posição que ocupam aqueles que as produzem no interior da estrutura de campo. (Bourdieu, op. cit, p. 134)

Diante desse terreno conflituoso, contraditório, de relações de poder e, também, de "ambigüidades" em que estão envolvidos os saberes pedagógicos, Tardif $(1991 ; 2004)$ aponta que esses saberes são primeiramente resultado da divisão do trabalho, na qual os professores universitários foram assumindo a pesquisa e os professores da escola básica a formação. Indica também que a relação moderna entre saber e formação possibilitou um deslocamento do foco dos saberes em si para os procedimentos de transmissão do saber. $\mathrm{O}$ que tem reduzido, certamente, a pedagogia ao domínio do como fazer. Explica ainda que essa desvalorização e esse despres- 
tígio do campo pedagógico têm relação com o aparecimento das ciências da educação, fazendo com que a pedagogia passasse a se subdividir em muitas especialidades. $\mathrm{O}$ que reduziu a mesma a campo aplicativo dessas ciências, perdendo assim a sua autonomia relativa, apesar dos ganhos. Tardif chama a atenção para o fato de que as instituições escolares são tratadas como uma questão pública. E, nesse sentido, tira um certo poder de autonomia relativa das instâncias educativas, dos profissionais da educação, pelo controle estatal dessas práticas, como apontam Nóvoa (1995b) e Enguita (1991), desfavorecendo a construção da profissão de professor, pelo não domínio e controle dos professores da sua própria prática. Por fim, enfatiza essa ambigüidade salientando a desconfiança dos diversos grupos sociais com relação aos saberes transmitidos pela escola, por avaliarem que estes têm pouca aplicabilidade na sociedade atual.

Considera-se que tais aspectos repercutem na formulação das políticas de formação dos profissionais da educação e na organização das diferentes agências formativas e contratantes desses profissionais. Entretanto, não obstante a importância dessas influências, uma perspectiva se vislumbra: a luta pela efetividade, antes de tudo, do papel educativo da Universidade, o que impóe a necessidade de se investir numa pedagogia e numa gestão universitária democráticas, que sejam sedimentadas pelos sentidos expressos ou implícitos de um dado projeto político-pedagógico institucional e de projetos de cursos, sintonizados criticamente com as demandas internas e externas; que favoreçam a irradiação/transversalização das suas práticas e permitam trocas entre práticas científicas, socioculturais e políticas diversas. Que tais práticas encontrem o seu núcleo formativo mais sistematizado de produção stricto sensu nas faculdades e centros de educação, instâncias que têm papel relevante junto aos sistemas de ensino, de fortalecer o estatuto epistemológico da pedagogia, como teoria educacional e pedagógica, de contribuir para a definição, implementação e avaliação de suas políticas e de preparar os quadros de pesquisadores, de gestores, de docentes demandados interna e externamente pela instituição e pela prática social.

Política de formação dos profissionais da educação, centralidade da pedagogia e demandas externas e internas

A instituição de uma política de formação dos profissionais da educação no interior das faculdades de educação e seus desdobramentos no 
Pedagogia e faculdades de educação: vicissitudes e possibilidades...

interior da Universidade, no momento atual, requer, em primeiro lugar, a abertura de espaço de discussão sobre a natureza da crise que marca a universidade pública no país e, em segundo lugar, sobre o sentido da pedagogia nos cursos de formação desses profissionais na aludida instância. Com base nesses aspectos, pode-se melhor entender os contornos da política de formação.

O que tem sido denominada crise da universidade (Santos, 1996) configura-se, de certa parte, como expressão das mudanças ocorridas nas diferentes instâncias da sociedade, atribuídas, sobretudo, aos processos de globalização econômica e cultural (homogeneizadores, hierarquizados e excludentes); à política neoliberal que advoga, de várias formas, um Estado mínimo, que amplia o espaço do privado em detrimento do público, dentre outras tantas questôes; aos avanços tecnológicos e científicos que, ao lado de suas positividades, vêm subordinando as práticas sociais, com base num modelo econômico de acumulação flexível que, ao se pautar pelo princípio fundante do mercado, no contexto do capitalismo global, tem exacerbado, por demais, os valores da competitividade, eficiência, produtividade, controle e individualidade.

Observe-se, nessa sobredeterminação de aspectos ${ }^{8}$ e condições globais, os desdobramentos na educação superior, num contexto de crise de legitimidade e hegemonia da Universidade (Santos, op. cit.), bem como de pressóes externas e internas por reformas educativas que centralizam o conhecimento e a qualificação profissional ajustados a essa nova ordem (Catani \& Dourado, 1999). Atente-se, nesse âmbito, para o fato de que um dos desdobramentos mais visíveis desses processos pode ser verificado nas dificuldades enfrentadas pelas universidades para pautar sua política institucional pari passu com a busca conflituosa pela materialização de um projeto coletivo, que se defina e avance em meio aos novos desafios, a partir da cultura instituída (Castoriadis, 1982; Veiga, 2000).

A construção desse projeto pressupõe uma gama variada de elementos: a reconstrução de conhecimentos e de práticas institucionais historicamente produzidas, como um processo de transição paradigmática, entre a lógica da racionalidade técnica e científica que suporta processos que intentam a privatização dessa instância e a lógica emergente direcionada para os processos educativos de publicização do "público", em que as práticas institucionais priorizam a efetivação da relação entre o global e o local, entre o conhecimento científico e o senso comum, com base na autonomia, liberdade e emancipação humana (Santos, 1989; 1996). 
Essa ruptura ensejada envolve uma forma de resistência que se manifesta em práticas concretas que buscam favorecer uma educação inclusiva, com base nos princípios da diversidade, no multiculturalismo emancipatório (Santos, 2001), como garantia dos direitos dos cidadãos, visando à construção de uma pedagogia como uma esfera contra-pública e uma política cultural (Giroux, 1997), como teoria e política civilizatória, voltada para a humanização das práticas e dos grupos. Tal direcionamento entra em choque com a lógica da exclusão e a do lucro associado intrinsecamente ao mercado (Sacristán, 1999).

Essas questôes presentes no debate nacional assumem maior importância, no país, dadas as anunciadas proposições governamentais em prol de uma reforma universitária ${ }^{9}$ - tema que tem suscitado polêmicas nos meios políticos, acadêmicos e sindicais, uma vez que se refere a projetos educacionais e, portanto, sociais, em disputa. Nesse debate, sobressai-se, como um dos temas recorrentes, a questão da autonomia universitária, o que suscita algumas indagações: Como resgatar a autonomia institucional na educação superior, de modo a superar a perspectiva operacional a-crítica que se configura na exacerbação técnica de meios, na burocracia cristalizada, em individualismos e dispersões que afetam o sentido político-pedagógico emancipatório (Saul, 1988) da institucionalização das reformas educativas? Como fortalecer a identidade dos loci da educação, de seus cursos, sem um esforço coletivo amplo de construção de uma cultura pedagógica interna, também avaliativa, que contribua para a definição dessa identidade, em meio à filtragem crítica das exigências mercadológicas externas? Como realizar tal intento, sem uma participação global e comprometida do corpo docente e discente e sem um projeto orgânico dos loci, em que os cursos de formação dos profissionais da educação, em especial, os cursos de pedagogia e licenciaturas, estão inseridos?

Dúvidas e inquietações desse teor, que perpassam o debate, evidenciam a complexidade das reformas da educação superior e o desafio teórico-prático a ser enfrentado nas instituições e nos seus cursos acadêmicos com vistas à construção de um projeto político-pedagógico crítico, coletivo e orgânico, com um sentido utópico e comprometido com a realização global e local de rupturas naquelas instâncias da educação, com vistas à humanização de suas práticas. Assim, a construção desse projeto, como resultado de uma decisão/adesão coletiva, mesmo que provisória, dá um norte, institucionalidade, legitimidade e organicidade às suas práticas (Veiga, 
Pedagogia e faculdades de educação: vicissitudes e possibilidades...

2004; Scheibe \& Aguiar, 1999). Sem essas materialidades, tudo parece indicar que ganha corpo, no interior das práticas universitárias, a reprodução da fragmentação, da operacionalidade a-crítica, da dispersão dos sujeitos e da pedagogia, o que dificulta a construção de uma pedagogia como teoria e discurso de síntese que envolve sentido ético-político, organização estética, cultural e pedagógica do espaço-temporal e do trabalho pedagógico. Não obstante, ressalte-se a importância das sinalizações dos discursos e das práticas dispersas emergentes, como ponto de partida, para a definição sistemática e intencional desse projeto, que não se confunde com os projetos acadêmicos de cursos.

O não enfrentamento de questões desse teor esvazia de sentido o debate sobre as reformas educativas, reduzindo-as a um modismo (Veiga, 2000; Aguiar, 1999), ou a uma importação a-crítica de imposições de instâncias externas, a exemplo das orientaçôes advindas de organismos multilaterais, reforçando, assim, a postura de agentes profissionais autômatos da funcionalidade operante, conforme dá margem a pensar (Chauí, 1999).

Outras problemáticas e condições básicas para a efetivação de uma política de formação dos profissionais da educação

Hodiernamente, no Brasil, na esteira das mudanças que se efetivaram na educação superior, desde a reforma gerencial do Estado, capitaneada pelo governo de Fernando Henrique Cardoso, um conjunto de fatores contribui para tolher a efetivação das funções essenciais das universidades públicas federais (Silva Jr., 2002). Atente-se, nesse sentido, para a realidade de uma política crescente de contratação de "professores substitutos" 10 em detrimento da contratação de docentes para compor o quadro efetivo, a precariedade de infra-estrutura ${ }^{11}$ que não condiz com as tarefas pedagógico-administrativas requeridas e a ausência de uma política consistente de valorização do magistério superior, questôes estas que têm limitado, em parte, a capacidade institucional de forjar ações mais favoráveis ao desenvolvimento pedagógico-político e cultural dos estudantes, particularmente nos cursos de formação dos profissionais de educação (professores da educação básica e pedagogos), sobretudo no ensino noturno.

Esse cenário suscita algumas questões: Será factível a formulação e implementação de uma política para a formação dos profissionais da educação, no âmbito das IFES, cuja base - a Pedagogia ${ }^{12}$ - seja eixo transver- 
sal formativo para toda prática educativa docente na universidade? Será que a formulação de tal política pode se processar apenas com a manutenção de um clima de efervescência em respostas às exigências de setores e de instituições externas, ou exigirá, de fato, a instauração de uma nova cultura pedagógica, que inclua uma nova cultura docente?

Será que as práticas universitárias têm em comum o trabalho pedagógico e docente que possibilite a instauração de uma nova cultura de direcionamento e organização das práticas na perspectiva da formação profissional e humana? Será que as práticas de ensino, pesquisa e extensão, resguardadas as suas especificidades, não se constituem no próprio terreno do ato pedagógico, como já defendiam Cunha (op.cit.) e Fernandes (1998)?

Nessa direção, estudos e pesquisas realizados em IES federais (Melo, 2004; Cunha, 1998b; 1998a; Fernandes, op. cit.) mostram que, muito embora haja sinalizaçóes de práticas emergentes, predomina, ainda, na Universidade e, em especial, nas faculdades de educação, a efetivação de práticas desarticuladas entre a graduação, a pós-graduação e os sistemas de ensino, o que expressa a dificuldade de materializar o princípio da indissociabilidade entre ensino, pesquisa e extensão como fazendo parte do próprio ato pedagógico-docente (envolvendo a relação professor-estudante).

A análise das práticas bem sucedidas, apontadas nessas pesquisas, revela que superar tal nível de desarticulação implica rever ou redirecionar políticas, no sentido de garantir a efetivação de determinadas condições básicas estruturais, conceituais, epistemológicas e pedagógicas. Isto implica discussões e tomadas de decisões compartilhadas, visando pautar normas de ordenamento do tempo/espaço coletivo e da produção e do trabalho pedagógico, bem como prover novas condições infra-estruturais. E nelas, a reestruturação dos departamentos, ou mesmo a sua extinção, numa nova lógica e estrutura institucionais. Nessa perspectiva, as múltiplas ações implementadas pelas faculdades de educação terão como eixo uma pedagogia centrada nos desafios contemporâneos internos e externos à instituição, o que permite uma dinamização mais diversificada do seu clima cultural e uma efetiva troca de conhecimentos e saberes. Isto pode favorecer ainda a materialização dos princípios cognitivos, ético-estéticos, técnico-científicos e pedagógicos nas práticas universitárias.

Desse modo, é factível a construção de um projeto político-pedagógico comum e particular ao mesmo tempo, ou seja, dar materialidade 
Pedagogia e faculdades de educação: vicissitudes e possibilidades...

a uma pedagogia universitária, que permita o estabelecimento de interfaces entre os diversos centros, faculdades, institutos, departamentos e cursos. Como alerta Bicudo (op. cit., p. 143-144), o desafio a ser enfrentado pelas universidades e faculdades de educação consiste em “'desocultar' a zona de intersecção entre ambas permitindo o encontro entre parceiros - de todas as áreas de atuação na universidade -, encontro este que possibilite a análise e a reflexão crítica de sua prática, abrindo-a a dúvidas, questionamentos e novas perspectivas".

Para a referida autora, essa realidade traz para a faculdade de educação o desafio do "comprometimento existencial e intelectual com a pesquisa a ser efetuada, de modo inter-transdisciplinar, em todas as áreas do conhecimento, objeto do ensino, da pesquisa e da extensão na universidade, e da obrigação de colocar-se no movimento dialético da construção histórica dessa realidade". Pelo ângulo das diversas áreas de conhecimento, o importante é que "deverão empenhar-se na postura de ouvir pessoas de outros setores falando de suas especialidades, ainda que de outra perspectiva, e, em uma atitude de respeito, analisar e refletir sobre o dito" (Bicudo, op. cit.).

Estes desafios expressam, de um lado, a necessidade da participação das faculdades de educação na política interna universitária, como também a presença das outras áreas nas pesquisas e práticas da educação, considerando a filosofia e as diversas dinâmicas que afetam a cultura institucional.

A efetivação de um projeto que atenda a esses requisitos supõe a construção de uma cultura participativa e avaliativa que contribua continuamente para o processamento de uma reflexão pedagógica (como práxis) sobre os acertos/desacertos das ações articuladas entre ensino, pesquisa e extensão.

O ponto nodal a ser efetivamente considerado concerne ao resgate/fortalecimento da especificidade do pedagógico em meio aos aportes teóricos, no interior dos diversos loci educativos, o qual precisa tornar-se um discurso de síntese, como um objeto próprio, no caso dos centros de educação, no curso de Pedagogia, e como conhecimento/ princípio transversal dos demais centros/áreas do conhecimento, constituindo-se, assim, como uma rede orientadora de fins, de valores, de organização do trabalho pedagógico e de lutas por melhores condições de trabalho de parte de todos os profissionais da educação, que encontram referência na docência como base dessa formação. 
Nesse contexto, ressalte-se a educação, a pedagogia e a atividade docente como uma práxis (Pimenta, 1996; Brzezinski, op. cit.; Ferreira, 2004) civilizatória, voltada para a formação humana em crise, no contexto da sociedade (Melo, 2002). Assim, partindo desse entendimento, as mínimas ações pedagógicas e administrativas ganham uma certa coerência, quando se materializam na sociabilidade cotidiana encontrando, assim, uma interconexão com as escolhas e metas político-institucionais da Universidade, de modo explícito e/ou implícito.

Aceitando-se essa perspectiva teórico-prática, impõe-se como meta a revisão das estruturas dos centros, faculdades de educação e dos seus departamentos (Kuenzer, 1996), no sentido da materialização de uma estrutura e de uma organização mais ampliada dessas instâncias, e, nelas, de uma prática curricular que contribua para a superação dos vieses linear, disciplinar e etapista, expressos na organização dos conhecimentos e das práticas. Tal revisão permitirá a emergência de práticas pedagógicas mais consistentes e articuladas também, em especial, a outras linguagens, no âmbito da universidade, em meio aos avanços da cultura informacional e da comunicação na sociedade (Barreto, 2004).

É interessante observar que a idéia de revisar a estrutura dos centros de educação, nas IFES, não mereceu a devida atenção, muito embora fosse defendida por alguns autores e movimentos, a exemplo da proposição da ANFOPE de formação unitária dos profissionais da educação (ANFOPE, 1992). Preterido, este assunto sempre foi deixado de lado com a promessa de que isto viria a ser discutido num tempo indefinido, o que deixa margem para se levantar a hipótese de que não haveria vontade política e mobilização suficientes para que, de fato, tal item fosse incluído, com prioridade, na agenda universitária. É possível que, subjacente a essa postura das IFES, estivesse claro que rever a estrutura organizacional das faculdades de educação significa enfrentar questões de poder, além de requerer muito investimento na cultura institucional e docente, visto que estas instâncias são concebidas como loci produtores, catalisadores de conhecimentos, saberes, ligados às atividades científicas e culturais diversas.

Ao prevalecer tal perspectiva, relegou-se o fato de que, contraditoriamente, a alternativa de re-estruturação dos centros no contexto de uma ampla reforma universitária apresenta-se prenhe de possibilidades de se construir o pedagógico em espaços diferenciados, flexibilizados e articulados de atuação, fazendo jus ao paradigma da pedagogia, que requer uma 
Pedagogia e faculdades de educação: vicissitudes e possibilidades...

estrutura e uma formação próprias de sujeitos que possibilitem a inter e/ ou transdisciplinaridade curricular.

Aderir a esta via, em meio aos limites e as possibilidades apontadas na prática institucional, requer o empenho das instâncias diretivas (especialmente, direção e coordenação) dessas faculdades e cursos, para interferir nas práticas da burocracia tão cristalizada ainda hoje nas instituições de ensino; para buscar a humanização dos espaços/tempos sociais, que favoreçam a efetivação de relações próximas com a comunidade acadêmica docente e discente; para agregação de esforços, na mobilização de conhecimentos da comunidade acadêmica e externa.

As pontuações feitas até aqui se traduzem numa utopia de formação de um profissional competente, comprometido com o seu tempo histórico, consciente da transformação dos desafios concretos da realidade em realizações voltadas para uma convivência social intercultural e uma educação mais democrática, solidária, justa e emancipatória. Que, nessa formação ampla, resguardem-se as especificidades epistemológicas e profissionais dos docentes.

A instituição de um projeto político-pedagógico que incorpore tal perspectiva se dá de forma conflituosa e implica a necessidade de uma ruptura nas práticas docentes academicistas, caracterizadas por projetos individualistas, demarcaçôes de territórios de conhecimentos, busca de "autonomias" fundadas no isolamento da sala de aula e de estudo/ jornada prolongada em casa e em outros serviços fora da universidade, como forma de complementação de salário e de atendimento às exigências da lógica produtivista e de regulação burocrática da sua prática (Weber, 2000), no contexto das suas situações precárias de trabalho (Oliveira, 2004) e de incentivo à sua carreira. A (re)significação dessas e de outras problemáticas existentes na cultura dos loci de educação implica desenvolver um processo de reflexão contínua como práxis, na perspectiva do desenvolvimento de uma formação pedagógica, que envolve mudança nos pressupostos dos sujeitos, na forma de compreensão de seus problemas e na sua própria postura para se tornar conceptor e gestor das práticas institucionais, curriculares e docentes.

Em suma, é nesse sentido que se elege a pedagogia, a pedagogia universitária, como projeto e eixo das práticas nas IES; como uma política que dá significado e sentido às práticas educativo-pedagógicas, na perspectiva da investigação, análise, explicação e intervenção nas mesmas; que 
forma condutas sociais compatíveis com o projeto; veicula e produz conhecimentos e culturas, num processo inter e transdisciplinar; que estabelece padrōes para o planejamento/gestão educacional e escolar, da docência universitária e da escola básica; como também para a construção de uma cultura avaliativa institucional. Isto, sem descurar do fato de que a qualidade da educação e da escola e a valorização dos profissionais da educação estão intrinsecamente vinculadas às políticas educacionais, determinadas pelas complexas e contraditórias relaçōes entre as classes e grupos sociais, que tem seus limites demarcados por novos condicionantes engendrados nos processos de globalização e transnacionalização do capitalismo e que afetam a autonomia do Estado. Nesse contexto, em que o Estado deixa de ser "produtor de bens e serviços para se transformar, sobretudo, em regulador do processo de mercado" (Afonso, 2001), as propostas e práticas que visam à mudança no plano educacional não poderão estar dissociadas das contendas e disputas pela afirmação de projetos político-sociais (e, portanto, educacionais) que tenham como norte a emancipação humana e a democracia.

\section{Recebido e aprovado em setembro de 2005.}

\section{Notas}

1. Entende-se por cultura tudo aquilo que potencia como restringe as possibilidades do desenvolvimento do indivíduo humano, sob a influência da herança social, das interaçóes humanas (Gómez, 2001), da história singular da vida do sujeito e das instituiçôes às quais pertence. Compõe, assim, o "conjunto de significados, expectativas e comportamentos compartilhados por um determinado grupo social, o qual facilita e ordena, limita e potencia os intercâmbios sociais, as produçōes simbólicas e materiais e as realizações individuais e coletivas dentro de um marco espacial e temporal determinado". Porém, possui, conforme Carspecken, apud Gómez (2001) "um certo e irredutível grau de autonomia que provoca disfunções, bloqueios, alternativas e, inclusive, a transformação das condiçõos de tal contexto". Segundo esse autor, "os fenômenos culturais precisam ser situados dentro do conflito das relaçōes sociais nas quais adquirem significação". Cultura e poder constituem assim "um casamento indissolúvel na vida cotidiana". Nesse estudo, transpõem-se esses significados, acerca da cultura, à compreensão da(s) cultura(s) pedagógica(s)-docentes, sem perder de vista as suas especificidades e a dos seus profissionais, conforme o artigo vem tratando.

2. A concepção sócio-histórica da educação, a que se refere este artigo, vem sendo construída nas esferas do debate nacional, da produção do conhecimento, da sociedade organizada e das práticas pedagógicas cotidianas, com significados próprios a autores e práticas, especialmente, a partir do final da década de 1970 e da criação do Comitê Nacional Pró-Formação do Educador (1980), que buscava, conforme Pino, a organização dos educadores, com vistas à elaboração de um projeto educacional participativo e crítico para o país, bem

Educ. Soc., Campinas, vol. 26, n. 92, p. 959-982, Especial - Out. 2005

Disponível em <http://www.cedes.unicamp.br> 
como visava contribuir para a reformulação dos cursos de pedagogia em crise nesse contexto, em face dos pareceres de Valnir Chagas. Essa concepção vem se constituindo como um projeto de resistência aos postulados educativos e curriculares tecnicistas, positivistas, de cunho a-crítico e a-histórico. Ver ANFOPE (1983); Saviani (1984; 1991), Rodrigues (1984); Libâneo (1985); Freitas (1985; 1987), Gadotti (1988).

3. Entende-se por base comum nacional, conforme pensamento da Associação Nacional pela Formação dos Profissionais da Educação (ANFOPE), uma diretriz que permeia o currículo como um todo, traz no seu bojo uma concepção sócio-histórica e crítica da educação, ancorada num corpo fundamental de conhecimentos (que não se confunde com currículo mínimo). Contempla quatro dimensões básicas - epistemológica, profissional, humana e política. Essa base intenciona permear amplamente as práticas curriculares universitárias formativas, na perspectiva de formar um perfil de profissional da educação comum, até certo sentido, uma vez que são resguardadas as especificidades dos diversos níveis e modalidade de ensino. Nesse entendimento, leva em consideração as sobredeterminações políticas, socioeconômicas, culturais, científicas de um dado contexto histórico e as subjetividades individuais e coletivas dos sujeitos que estão envolvidos no processo educacional. Em particular, enfatiza um vínculo orgânico e dinâmico com a realidade da escola básica $\mathrm{e}$ a realidade não-escolar e, também, com o debate nacional crítico, acerca da educação, pedagogia e docência, sob o aporte das ciências sociais e humanas.

4. Entende-se profissionalidade num sentido dinâmico, na perspectiva do desenvolvimento profissional e de busca de autonomia, em certo sentido, em que o profissional da educação/docente vai construindo os saberes necessários/específicos ao exercício de sua profissão nas práticas educativas diversas e de ensino. Constitui um processo de reflexão pedagógica compartilhada e contínua sobre a sua prática, que se efetiva mediante interações, socializações profissionais, pessoais e institucionais sucessivas. Nesse processo, não se exime a responsabilidade das instituições formativas e contratantes, nem tampouco o incentivo das políticas de formação continuada, no sentido de criar condiçôes concretas para atualização/aperfeiçoamento profissional, como também o compromisso do profissional com a instituição. Essa concepção encontra respaldo em Nóvoa (1995); Gómez (2001); Dubar (1997); Lüdke (2004); Foerste apud Lüdke (2004).

5. Entende-se profissionalização do magistério, ou num sentido mais amplo, do profissional da educação, como um conjunto imbricado de processos/movimentos que se articulam na direção de promover condições satisfatórias para a melhoria da formação e identidade profissionais, tais como: a) formação inicial articulada à formação continuada; b) construção democrática e justa da carreira profissional com amplo reconhecimento social, junto às garantias salariais e às condições de trabalho condignas do profissional; c) domínio de conhecimentos e saberes especializados e valores necessários à sua condição de profissional e de cidadão(ã), gerados na relação intrínseca entre a formação e o trabalho (articulação orgânica entre as agências formativas e contratantes); d) conscientização do profissional quanto à importância da sua condição profissional com independência e autonomia perante as burocracias estatais e institucionais; e) código de ética funcionando como um " controle social" mais amplo na sociedade. Muitos autores vêm contribuindo, cada um dentro do seu modo particular de enfrentar essa questão, para essa compreensão de profissionalização, como Nóvoa (1996); Enguita (1991); Tardif (2000); Alarcão (1998); Weber (2003): Lüdke (2004); Brzezinski (2002). Vide documentos da ANFOPE. Disponível em: <www.lite.fae.unicamp.br/anfope>. Acesso em: jun. 2005.

6. A partir dessa página vamos identificar essas instâncias de faculdades de educação pela justificativa histórica de sua gênese legal, sabendo-se das diferenças entre elas.

7. Esse reconhecimento pode ser constatado, por exemplo, nos debates realizados na usp, por ocasião dos trinta anos da Faculdade de Educação da Universidade de São Paulo, em 1999. 
8. Ver Jameson (1996).

9. Sobre esse assunto, consultar documentos do MEC e de outras entidades. Disponível em: <www.mec.gov.br>. Acesso em: 20 jul. 2005.

10. Professores com vinculação temporária nas IFES.

11. Em algumas IEs há diferenças internas, quanto à infra-estrutura, entre os centros e faculdades/departamentos.

12. A Pedagogia, nessa perspectiva, como uma teoria educacional e pedagógica (Freitas, 1987), é portadora de uma identidade própria (autonomia relativa que tem como objeto a educação na relação intrínseca com o ensino). É considerada ciência da prática social da educação (Pimenta, 1996; 1997) e situa-se no plano das dimensões dos fins, dos valores, da praxiologia, da organização da prática pedagógica (Libâneo, 1996; 1999b) e também nos terrenos da técnica/arte, da improvisação, do talento artístico, do saber tácito, com base em Shön (1992), Tardif (2002) e especialmente em Zeichner (1993), que avança para uma visão reflexiva da prática pedagógica enquanto práxis. Nesse sentido, a pedagogia é orientada por um paradigma complexo, onde se articulam dialeticamente conhecimentos e discursos da pedagogia, das ciências da educação, discursos especializados de outras ciências e de outras intelectualidades, saberes construídos na prática, onde, pela mediação do discurso pedagógico, junto a esses diversos discursos, eles são recontextualizados/transformados em conhecimentos escolares (Bernstein, 1996). O papel da Filosofia , como também das outras ciências da educação, é importante nessa recontextualização para a formação de um pensamento abrangente-analítico dos profissionais da educação, como para a compreensão/execução fundamentada do trabalho pedagógico. Assim, o enfoque da pedagogia se justifica pela multidimensionalidade e multirreferencialidade, de modo recontextualizado, para fortalecer a sua especificidade na relação entre a ação educativa e a docente.

\section{Referências bibliográficas}

AFONSO, A.J. Reforma do Estado e políticas educacionais: entre a crise do Estado-nação e a emergência da regulação supranacional. Educação \& Sociedade, Campinas, v.22, n. 75, p.15-32, ago. 2001.

AGUIAR, M.A.S. A formação do profissional da educação no contexto da reforma educacional brasileira. In: FerReira, N.S.C. (Org). Supervisão educacional para uma escola de qualidade. São Paulo: Cortez, 1999.

AGUIAR, M.A.S. Espaço da gestão na formação do profissional da educação. In: Ferreira, N.S. C.; Machado, L.M. Politica e gestão da educação: dois olhares. Rio de Janeiro: DP\&A, 2002a.

AGUIAR, M.A.S. A formação dos profissionais da educação básica no curso de pedagogia. In: Ferreira, N.S.C.; Aguiar, M.A.S. (Org.). Para onde vão a orientação e a supervisão educacional. 2. ed. Campinas: Papirus, 2002b.

Educ. Soc., Campinas, vol. 26, n. 92, p. 959-982, Especial - Out. 2005

Disponível em <http://www.cedes.unicamp.br> 
Pedagogia e faculdades de educação: vicissitudes e possibilidades...

ALARCÃO, I. Formação continuada como instrumento de profissionalização docente. In: VeIGA, I. (Org.). Caminhos da profissionalização do magistério. Campinas: Papirus, 1998.

BARRETO, R.G. Tecnologia e educação: trabalho e formação docente. Educação \& Sociedade, Campinas, v. 25, n. 89, p. 1181-1201, dez. 2004.

BERNSTEIN, B. A estrutura do discurso pedagógico: classe, códigos, controles. Petrópolis: Vozes, 1995.

BICUDO, M.A.V. Faculdade de educação e universidade. In: KRASILCHIK, M. (Org.) Faculdades de educação: realizações e desafios. São Paulo: FEusp, 2000. p. 139-148.

BOURDiEU, P. O campo científico.In: Ortiz, R. (Org.). Pierre Bourdieu. São Paulo: Ática, 1994.

BRITO, R.L.G.L. Escola: cultura, clima e formação de professores. In: Queluz, A.G. et al. (Org.). O trabalho docente: teoria e prática. São Paulo: Pioneira, 1999.

BRZEZINSKI, I. Pedagogia, pedagogos e formação de professores. São Paulo: Papirus, 1996.

CATANI, A.M.; DOURADO, L.F. (Org.). Universidade pública: políticas e identidade institucional. Campinas: Autores Associados; Goiânia: UFMG, 1999.

CHAUI, M. A universidade operacional. Folha de S. Paulo, São Paulo, 9 maio 1999, Caderno Mais!, p. 5-3.

CUNHA, L.A. A universidade critica. Rio de Janeiro: Francisco Alves, 1983.

CUNHA, M. I. O professor universitário na transição de paradigmas. Araraquara: JM, 1998a.

CUNHA, M.I. Aportes teóricos e reflexões da prática: a emergente reconfiguração dos currículos universitários. In: MAsSETO, M. (Org.). Docência na universidade. Campinas: Papirus, 1998b.

CUNHA, L.A. Universidade para quê? Palestra conferida na Fundação Mangabeira, promovida pela ADUFEPE, Recife, 1999. (texto digitado). 
DUBAR, C. A socialização: construção das identidades sociais e profissionais. Porto: Porto, 1997.

ENCONTRO NACIONAL DA ASSOCIAÇÃO NACIONAL PELA FORMAÇÃO DOS PROFISSIONAIS DA EDUCAÇÃO (ANFOPE), 6., 1992, Belo Horizonte. Documento final. Belo Horizonte, 1992. Disponível em: <www.lite.fae.unicamp.br/anfope> Acesso em: nov. 2004.

ENGUITA, M. A ambigüidade da docência: entre o profissionalismo e a proletarização. Teoria \& Educação, Porto Alegre, n. 4, p. 109-139, 1991.

FERNANDES, C.M.B. Formação do professor universitário: tarefa de quem? In: Masetto, M. Docência na universidade. Campinas: Papirus, 1998.

FÉTIZON, B.A.M. Faculdades de educação: antecedentes e origens. Estudos Avançados, São Paulo, v. 8, n. 22, p. 365-73, 1994.

FREITAS, H.C.L. O trabalho como princípio articulador na prática de ensino e nos estágios. Campinas: Papirus, 1996.

FREITAS, H.C.L. A reforma do ensino superior no campo da formação dos profissionais da educação básica: as políticas educacionais e o movimento dos educadores. Educação \& Sociedade, Campinas, v. 20, n. 68, p. 17-43, dez. 1999.

FREITAS, L.C. Notas sobre a especificidade do pedagogo e sua responsabilidade no estudo da teoria e da prática pedagógica. Educação \& Sociedade, Campinas, v. 7, n. 22, p. 12-19, 1985.

FREITAS, L.C. Projeto histórico, ciência pedagógica e didática. Educação \& Sociedade, Campinas, v. 9, n. 27, p. 122-140, 1987.

FREITAS, L.C. Neotecnicismo e formação do educador. In: Alves, N. (Org.). Formação de professores: pensar e fazer. São Paulo: Cortez, 1992a.

FREITAS, L.C. Crítica da organização do trabalho e da didática. Campinas: Papirus, 1995.

GADOTTI, M. Educação e compromisso. Campinas: Papirus, 1988.

GIROUX, H. Os professores como intelectuais. Porto Alegre: Artes Médicas, 1997. 
Pedagogia e faculdades de educação: vicissitudes e possibilidades...

JAMESON, F. Pós-modernismo: a lógica do capitalismo tardio. São Paulo: Ática, 1996.

KRASILCHIK, M. Faculdade de Educação da USP: 30 anos. In: Krasilchik, M. (Org.). Faculdades de Educação: realizações e desafios. São Paulo: FEUSP, 2000. p. 11-20.

KUENZER, A.Z. A formação de educadores: novos desafios para as faculdades de educação. In: ENCONTRO NACIONAL DE DIDÁTICA E PRÁTICA DE ENSINO, 8., 1996, Florianópolis. Anais... Florianópolis: UFSC, 1996. v. 2.

LÜDKE, M.; BOING, L. A.. Caminhos da profissão e profissionalidade docente. Educação \& Sociedade, Campinas, v. 25, n. 89, p. 1154-1180, dez. 2004.

MARCOVITCH, J. Pronunciamento. In: KrasilchiK, M. (Org.) Faculdades de educação: realizações e desafios. São Paulo: FEusP, 2000. p. 7-10.

MELO, M.M.O. A construção do saber docente: entre a formação e o trabalho. 2000. Tese (Doutorado) - Faculdade de Educação, Universidade de São Paulo, São Paulo.

MELO, M.M.O. As crises da sociedade e seus desdobramentos sobre o currículo e a docência universitária. Goiânia: ENDIPE, 2002. (CD-ROM).

MELO, M.M.O. Política de formação dos profissionais da educação: desafios para construção de uma nova cultura pedagógica e docente na universidade. In: ENCONTRO NACIONAL DE DIDÁTICA E PRÁTICA DE ENSINO, 12., 2004, Curitiba. Anais... Curitiba, 2004. (CD-ROM).

NÓVOA, A. A formação de professores e profissão docente. In: NóvOA, A. (Org.). Profissão professor. Lisboa: Dom Quixote; Instituto de Inovação Educacional, 1995a.

NÓVOA, A. (Org.). As organizaçôes escolares em análise. Lisboa: Dom Quixote, Instituto de Inovação Educacional, 1995 b.

OLIVEIRA, D.L. A reestruturação do trabalho docente: precarização e flexibilização. Educação \& Sociedade, Campinas, v. 25, n. 89, p. 1127 1144, dez. 2004.

PIMENTA, S. G. As ciências de educação e os processos de mudança. 
In. Pimenta, S.G. Pedagogia, ciência da educação? São Paulo: Cortez, 1996.

PIMENTA, S.G.; LIBÂNEO, J.C. Formação dos profissionais da educação: crítica e perspectivas de mudanças. In: Pimenta, S.G. (Org.). Pedagogia e pedagogos: caminhos e perspectivas. São Paulo: Cortez, 2002.

RODRIGUES, N. Por uma nova escola: o transitório e permanente na educação. São Paulo: Cortez; Campinas: Autores Associados, 1986.

SACRISTÁN, J.G. Docência y cultura escolar: reformas y modelo educativo. Buenos Aires: Lugar Editorial; Idéias, 1997.

SACRISTÁN, J.G. Poderes instáveis em educação. Porto Alegre: Artes Médicas, 1999.

SANTOMÉ, J.T. Globalização e interdisciplinaridade. Porto Alegre: Artes Médicas, 1998.

SANTOS, B. S. Introdução a uma ciência pós-moderna. Rio de Janeiro: Graal, 1989.

SANTOS, B.S. Pela mão de Alice: o social e o político na pós-modernidade. São Paulo: Cortez, 1996.

SANTOS, M. O professor como intelectual na sociedade contemporânea. In: ENCONTRO NACIONAL DE DIDÁTICA E PRÁTICA DE ENSINO, 9., 1998, Águas de Lindóia. Conferência de abertura. Águas de Lindóia, 1998.

SAUL, A.M. Avaliação emancipatória: desafio à teoria e á prática de avaliação e reformulação de currículo. Campinas: Autores Associados, 1988.

SAVIANI, D. Escola e democracia: teorias da educação, curvatura da vara, onze teses sobre educação e política. São Paulo: Cortez; Campinas: Autores Associados, 1984.

SAVIANI, D. Pedagogia histórico-crítica: primeiras aproximaçóes. São Paulo: Cortez; Campinas: Autores Associados, 1991.

SCHEIBE, L; AGUIAR, M.A. Formação de profissionais da educação no Brasil: o curso de pedagogia em questão. Educação \& Sociedade, Campinas, v. 20 , n. 68 , p. 220-238, dez. 1999. 
Pedagogia e faculdades de educação: vicissitudes e possibilidades...

SCHÖN, D.A. Formar professores como profissionais reflexivos. In. NóvoA, A. (Org.). Os professores e a sua formação. Lisboa: Dom Quixote, 1992.

SILVA JR., J.R.S. Reforma do Estado e da educação no Brasil de FHC. São Paulo: Xamã, 2002.

TARDIF, M. Os professores face ao saber: esboço de uma problemática do saber docente. Teoria \& Educação, Porto Alegre, n. 4, p. 215-233, 1991.

TARDIF, M. Saberes docentes e formação profissional. Petrópolis: Vozes, 2002.

TEIXEIRA, L.H. Cultura organizacional da escola: uma perspectiva de análise e conhecimento da unidade escolar. Revista Brasileira de Politica e Administração da Educação, Porto Alegre, v. 1, n. 1, jan./jun. 1983.

UNIVERSIDADE FEDERAL DE PERNAMBUCO. Coordenação de Pedagogia. Reforma do curso de pedagogia. ago. de 2002. (Documento).

VEIGA, I.P.A. Projeto político-pedagógico: continuidade ou transgressão para acertar? In: VEIGA, I.P.A. O que há de novo na educação superior: do projeto pedagógico à prática transformadora. Campinas: Papirus, 2000.

WEBER, S. Políticas do ensino superior: perspectivas para a próxima década. Avaliação, Campinas, v. 5, n. 1, mar. 2000.

WEBER, S. Faculdades de educação e formação de professores. In: KrasilchiK, M. (Org.). Faculdades de educação: realizações e desafios São Paulo: FEUSP, 2000. p. 127-138.

WEBER, S. Profissionalização docente e políticas públicas no Brasil. Educação \& Sociedade, Campinas, v. 24, n. 85, p. 1125-1154, 2003.

ZABALA, A. A prática educativa: como ensinar. Porto Alegre: Artes Médicas, 1998.

ZEICHNER, K.M. A formação reflexiva de professores: idéias e práticas. Lisboa: Educa, 1993. 